\title{
Comment Re: "Traumatic brain injuries in illustrated literature: experience from a series of over 700 head injuries in the Asterix comic books"
}

\author{
Nikolas Lloyd
}

Received: 5 September 2011 /Accepted: 27 September 2011 /Published online: 19 October 2011

(C) Springer-Verlag 2011

\section{Dear Editor,}

I read with some dismay the abstract of the paper entitled "Traumatic brain injuries in illustrated literature: experience from a series of over 700 head injuries in the Asterix comic books (Acta Neurochir 153: 1351-1355)".

This research is useless without a follow-up study to examine the condition of the sufferers of the head injuries some considerable while later (I would recommend tests at 1 month, 3 months, and 2 years), compared with a control group.

'Roman nationality' is stated to be a correlate with TBI, and yet this category is genetically meaningless, given the wide span of the Roman Empire and the great genetic variation of the citizenry. Also, many in the Roman army were not citizens at all, because service in the army was a way to gain citizenship. There is no way to tell from the pictures in the books alone, which form the sole database, whether the soldiers shown suffering TBIs are citizens or not, making the correlation calculations based on 'nationality' extremely unreliable.

Further, no investigation was made into the dosage of potion given to those inflicting the TBIs, nor even to the consistency of the ingredients of this doping agent, and so no firm conclusions can be drawn as to its effectiveness, nor even relevance. Were any Gauls given a placebo potion against which the medical efficacy of the supposedly active potion might have been measured? A double-blind test would surely have been appropriate here. Reporting a correlation without communicating any understanding of the role played by an observed correlate does not establish cause and effect.

I find it depressing that such bad science is presented as a useful contribution to research, using the feeble excuse of the scandalously opaque 'peer review' system.

Conflicts of interest None.

N. Lloyd $(\bowtie)$

Mandeville Enterprises,

35 Ashfield Road, Gosforth,

Newcastle upon Tyne NE3 4XL, UK

e-mail: nikolas.lloyd@googlemail.com 